Pre-print text for column in 'Information Development' - Volume 27, Issue 2, Date May 2011, pp.92-93

Education for Librarianship and Information Studies: Fit for Purpose?

\title{
Bibliometrics and the brain dead
}

\author{
Ian M. Johnson \\ Professor, Department of Information Management, Aberdeen \\ Business School, The Robert Gordon University, Garthdee Road, \\ Aberdeen AB10 7QE, Great Britain (i.m.johnson@rgu.ac.uk)
}

\begin{abstract}
Many bibliometric and webometric studies are superficial, failing to explore the reasons underlying the phenomenon that they measure. Why do so many LIS researchers show so little curiosity about the context within which information is produced and used? Why do they neglect this opportunity to demonstrate the importance of information to development? What more do teachers need to communicate about the purpose of bibliometrics and how to apply them in an influential way?
\end{abstract}

As a journal editor or referee, I am asked to look at numerous bibliometric studies every year. Most of them have been a waste of the authors' time, as well as mine. Scientometrics, bibliometrics and webometrics are not new techniques, but most of these papers are aimless. Too many authors of such papers have not even asked themselves what the purpose of their paper is and what problem it will solve. They provide too much description of the characteristics of journals and make too little effort to put these facts into perspective. In a specious attempt to imitate scientific method, many papers do little more than demonstrate that the authors can count and categorise - and that the teaching of bibliometrics has been seriously deficient.

Before they begin, why do authors of bibliometric studies not realise that they need to look beyond the numeric results to ask - "why is this situation occurring?" In one paper that I saw a few months ago, the authors (librarians) did at least attempt to take things further by considering the link between the published outputs from a country and its wealth, as expressed by its Gross Domestic Product (GDP), but all they did was establish that there does appear to be a link. Another paper, by a scientist, produced data comparing several countries' GDP, populations and the number of papers in ISI. He compiled ratios of published output to GDP and to population, but did not produce any evidence to try to explain some quite apparent and very significant variations. The link between the state of library provision in a country and its GDP was demonstrated in a PhD thesis by Jesus Lau some 30 years ago.' It appears that knowledge has 
moved on very little in that time - and much less than might be expected given the volume of bibliometric activity and the existence of at least one international conference focused on it.

Many bibliometric studies enumerate the extent and scope of scientific communication and collaboration amongst researchers. What is important is to try to understand the cause of these linkages - and that means exploring many more factors than the authors usually even acknowledge. There is, for example, no mention of linguistic barriers to communication; of the places where individuals have studied; of the strengths and weaknesses of publishing industries in developing countries in helping to establish the reputations on which collaborations are built; or of the opportunities for individuals to attend conferences where the 'invisible colleges' meet.

Some studies that I have been offered for publication considered the papers in a single journal, and conclude that this publication is important without even attempting to show where articles from the publication are cited. More importantly, without comparing it with other journals in the same discipline, and without evaluating the impact of the papers that it alone has published on scientific progress in the discipline or on the economic progress of a country, how could such a conclusion be reached?

Some have considered the authorship pattern of papers in the journals relating to one industry or product, without demonstrating any relationship between the content of papers in the journals to developments in the industry. Whether papers are single or joint authored is meaningless, unless there is some significance in the collaboration, e.g. in introducing the innovations of one of the authors into an industry or company previously ignorant of his work, in providing some evidence that the quality of research, as confirmed by the standing of the collaborator, has had any impact on the reputation or promotion of particular researchers.

But good science can also prove that something is not possible or is not working and needs to be fixed. Too many of the bibliometric studies that I see reach no meaningful conclusion; they simply imply that authors and publishers are doing a good job. Critical evaluation is all too often absent.

Other studies count the outputs of scientists in a single institution or country, or in a particular discipline in a country, without revealing and explaining any trends compared with the nationally or internationally published research output of the institution, country, or discipline concerned which would demonstrate their standing in their international peer group. The heads of many universities in the less developed countries aspire to develop the international standing of their institutions, but this is significantly influenced by academics' employment environment. Researchers interested in human resource management in LIS in developing countries have begun to explore topics such as the differences in pressure on academic staff to teach and/or research and write for publication; fiscal pressures that compel many academics to devote their energies to working outside their university as paid consultants when they are not teaching; or the availability of research time and funds. Where is the evidence brought together to demonstrate the impact of these environmental factors on their published output (and reputation), and on the development of the country, in a way that 
helps senior managers to make a case for the internal changes and the reallocation of government resources that are necessary to raise the profile of their institution?

One is left with the impression that since Garfield invented ISI and its enumeration of citations, everyone has sat back, satisfied that the 'idea' has been demonstrated to work. But any understanding of the idea and its potential seems to have been lost. It is surely time for someone to start to bring the bibliometric data with the factors that contribute to development together in a coherent discussion? Sadly, the authors of so many bibliometric studies do not seem to have the breadth of awareness to begin even to start that task. Librarians' lack of curiosity, narrowness of vision, and inability to consider, let alone comprehend data from other disciplines come together in a total negation of their professional responsibility. Should these failings be attributed to the pattern of professional education in countries in which librarians have little or no education in anything other than professional subjects, and/or in which so-called professional education is task-oriented rather than exploring the purpose of libraries and emphasising the policies that assure their success? Or are they attributable to uninformed, uninspired and uninspiring teaching, which transmits the failings of one generation on to the next?

There have been a few informative and influential studies based on the use of bibliometrics, but most of those librarians and information specialists who seek to produce bibliometric studies need to be reminded that the majority of scientific papers in all disciplines are rejected by significant journals because they contain trivial, inaccurate, or false conclusions. The starting point for a bibliometric study, as with the preparation of any paper, is to determine the research questions(s) and how the evidence will be gathered to answer those questions. A little honest self-evaluation about what the potential significance of the results might be and who might be interested in them would also be useful.

Most of the indexes available online today started out as an individual librarian's efforts to assist the users of a specialist library. Bradford and Garfield also thought that they were working to improve the quality of information services. Is the same sense of commitment to enhancing the effective use of information reflected in current approaches to the teaching of bibliometrics?

\section{January 2011}

\footnotetext{
' Lau, J. 1988. A study of the socio-economic factors influencing information development in low, middle, and highly developed countries. PhD Thesis. Sheffield, UK: University of Sheffield
} 